\title{
Welcome to Volume 12 of the journal Future Virology
}

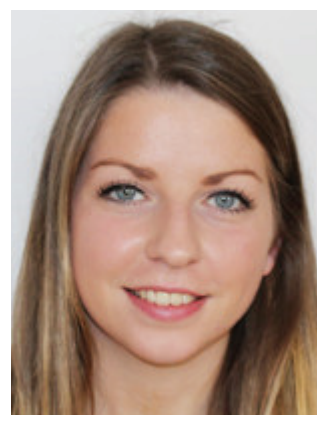

Frances Adlam*,1

\author{
“Future Virology's most read article of 2016 was an Editorial \\ entitled 'Zika virus: an emerging arboviral disease' by \\ authors Neelima Arora, Mangamoori Lakshmi Narasu and \\ Amit K Banerjee...”
}

Future Virology would like to wish all of its readers a Happy New Year and introduce you all to the 12th volume of the journal. Year 2016 was another successful year for our published articles and was also the 10th year anniversary for Future Virology! I would like to begin this year by thanking our Editorial Board members, readers and contributing authors for their continued support and valuable opinion in the virology field. Below you will find the journals content highlights among other updates from the past year.

\section{Content highlights of 2016}

Future Virology's most read article of 2016 (from January 2016 to October 2016) was an Editorial entitled 'Zika virus: an emerging arboviral disease' by authors Neelima Arora and Mangamoori Lakshmi Narasu from Jawaharlal Nehru Technological University, and Amit K Banerjee from Indian Institute of Chemical Technology (all from Telangana, India) [1]. Since the recent Zika Virus outbreak in the Americas, there has been a sharp rise in arboviral research. This article provides a compact overview of this, starting at the first outbreak of Zika through to its transmission, virology, symptoms, diagnosis and treatment. This short article highlights the importance of surveillance and control programs that would inevitably be important to prevent a new pandemic in new areas.

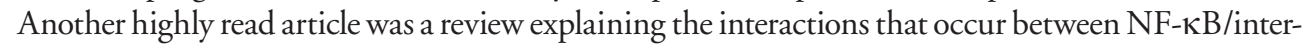
feron signaling and HPV genome replication during the HPV life cycle. Written by National Cancer Center Research Institute (Tokyo, Japan) researchers Tomomi Nakahara and Tohru Kiyono, this article describes the mechanisms involved that allow HPV to persist in the epithelium in its dormant state [2].

Developing new influenza vaccines each year is paramount due to the high mutation rates and the segmented nature of the virus. Two more of our most popular read articles of 2016 look at this area. An Editorial by Yo Han Jang and Baik Lin Seong from Yonsei University (Seoul, South Korea) revisits research from recent years, describing the efforts that have been made to create a universal influenza vaccine [3]. Further to this, a short opinion piece by Jun Wang from the University of Arizona (AZ, USA) looks at M2 as a potential target to combat influenza drug resistance [4].

Following our collaboration with Altmetric in 2015, a particular acknowledgment goes to the following articles which have received the highest scores throughout Future Virology's 10 years of publication:

- Our highest score was for the review article entitled: 'The pathogenesis of chronic chikungunya: evolving concepts' written by Rueshandra Roosenhoff, Fatih Anfasa \& Byron Martina [5] Altmetric score: 31;

'FutureScience Group, Unitec House, 2 Albert Place, London N3 1QB, UK

*Author for correspondence: f.adlam@futuremedicine.com

\section{KEYWORDS}

- chikungunya • ebolavirus

- filovirus • HPV • influenza

- virology • Zika virus 
- Next was the review article entitled 'Ebolavirus glycoprotein structure and mechanism of entry' written by Jeffrey E Lee \& Erica Ollmann Saphire [6] - Altmetric score: 26;

- The third highest score was for the review article: 'Filovirus replication and transcription' written by Elke Mühlberger [7] - Altmetric score: 13 .

\section{Reader demographic}

It is of great interest to see the main areas of the world in which Future Virology's content is having the highest influence. In 2016, the largest proportion of our readers came from the USA (32\%), followed by Europe (excluding the UK) (19\%) and Brazil (16\%) (Figure 1). Despite this readership being centered in the Americas and Europe, we are delighted to see our content reach other areas of the globe and hope to observe a continued widespread in the years to come.

\section{Social media}

Future Virology remains active across the social media platforms; twitter (@fsgfvl) and LinkedIn [8]. Discussing the most recent research in the virology field while also posting the journals highlights and newly published articles, we continue to enjoy interacting with our readers and experts in the field.

\section{Conclusion}

As always, we greatly appreciate any feedback the virology community wishes to share whether it is on key topics that you feel should be covered or where you see the field going in the future. We welcome unsolicited article proposals and would be pleased to hear from you. In particular, we are looking for submissions on:

- The molecular basis of viral diseases;

- Overviews highlighting optimal therapeutic and diagnostic approaches, along with potential future options;

- Summaries evaluating newly approved antiviral agents;

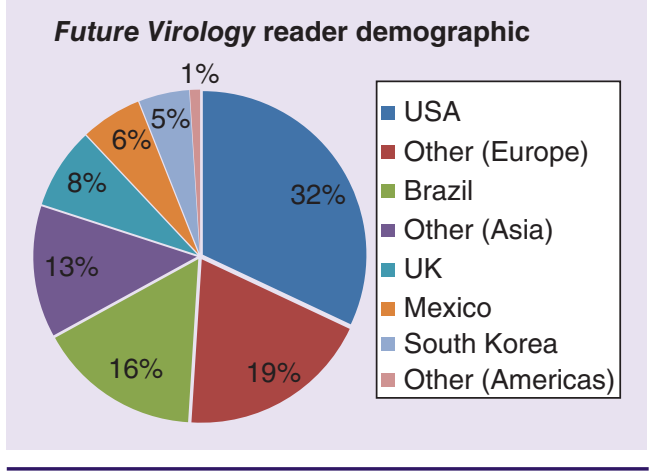

Figure 1. Proportion of readership demographics for Future Virology in 2016.

- Adverse events and drug safety;

- Pharmacoeconomics and cost-benefit issues in virology;

- New and re-emerging viruses;

- Epidemiologic studies and trends;

- The problem of viral drug resistance and potential methods to overcome this;

- Vaccine development and the prevention of viral diseases;

- The use of viral vectors in gene therapy and functional genomics;

- Defense against the use of viruses in bioterrorism.

I look forward to hearing from many of you in the coming year and to continuing to publish content as high quality as those we saw in 2016.

Financial \& competing interests disclosure

$F$ Adlam is an employee of Future Medicine Ltd. The author has no other relevant affiliations or financial involvement with any organization or entity with a financial interest in or financial conflict with the subject matter or materials discussed in the manuscript apart from those disclosed.

No writing assistance was utilized in the production of this manuscript.

3 Jang YH, Seong BL. Toward a universal influenza vaccine: a retrospective. Future Virol. 11(5), 313-316 (2016).

4 Wang J. M2 as a target to combat influenza 
drug resistance: what does the evidence say? Future Virol. 11(1), 1-4 (2016).

5 Roosenhoff R, Anfasa F, Martina B. The pathogenesis of chronic chikungunya: evolving 7 concepts. Future Virol. 11(1), 61-77 (2016).
6 Lee JL, Saphire EO. Ebolavirus glycoprotein structure and mechanism of entry. Future Virol. 4(6), 621-635 (2009).

7 Mühlberger E. Filovirus replication and transcription. Future Virol. 2(2), 205-215 (2007).
8 Future Science Group Microbiology. www.linkedin.com/ 